\title{
REVISTAMARACANAN
}

Dossiê

\section{O Verme da Guiné e a coleção de helmintos do Instituto Oswaldo Cruz (CHIOC)}

\author{
The Guinea worm and the helminthological collection of the Oswaldo Cruz \\ Institute (CHIOC)
}

Olivia da Rocha Robba*

Universidade de São Paulo

São Paulo, São Paulo, Brasil

Keith Valéria Barbosa** Universidade Federal do Amazonas Manaus, Amazonas, Brasil

Recebido em: 25 jan. 2021.

Aprovado em: 01 jun. 2021.

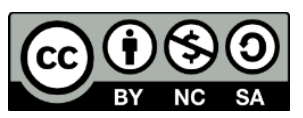

\footnotetext{
* Doutoranda em História Social (PPGHS-USP) e Mestre em História das Ciências e da Epistemologia (HCTEUFRJ). Bacharel e Licenciada em História pela UFRJ (IFCS-UFRJ) e Especialista em preservação e gestão do Patrimônio das Ciências e da Saúde (COC-FIOCRUZ). (oliviarobba@usp.br)

(C) https://orcid.org/0000-0002-8322-8785 (6 http://lattes.cnpq.br/4268926125296480

** Professora Adjunta de História da África da Universidade Federal do Amazonas (UFAM). Doutora em História das Ciências e da Saúde pela Fundação Oswaldo Cruz - FIOCRUZ e Mestre em História pela Universidade Federal Rural do Rio de Janeiro (UFRRJ).(keithbarbosa@hotmail.com)

(2) https://orcid.org/0000-0002-1340-6515 (6) http://lattes.cnpq.br/3692449762532927
} 


\title{
Resumo
}

O artigo tem como objetivo analisar o verme africano coletado por Oswaldo Cruz, o Dracunculus Medinensis Linneaeus, também conhecido como 'verme da Guiné', causador da dracunculose, que faz parte da Coleção Helmintológica do Instituto Oswaldo Cruz (CHIOC) e foi encontrado parasitando o tecido subcutâneo de um homem no início do XX. Pretende-se, a partir desta amostra, discutir a importância das coleções científicas como objeto de estudo para a história das ciências, a presença do verme no Brasil e a ausência da disseminação da doença causada por ele, o que revela a dinâmica da relação entre hospedeiro e parasita no contexto social de transformações do século XIX, período caracterizado pelo intenso circuito transatlântico entre América e África.

Palavras-chave: Doença de Escravo. História da Saúde e das Doenças. Dracunculose. Verme da Guiné. Coleções Científicas.

\begin{abstract}
This paper aims at analyzing the African worm collected by Oswaldo Cruz, Dracunculus Medinensis Linneaeus, also known as 'Guinea worm', which causes dracunculiasis, which is part of the Helminthological Collection of the Oswaldo Cruz Institute (CHIOC) and was found parasitizing the subcutaneous tissue of a man at the beginning of 20th century. Based on this display, we discuss the importance of scientific collections as an object of study for the history of sciences and the presence of the worm in Brazil and the absence of the spread of the disease caused by it which reveals the dynamics of the relationship between host and parasite in the social context of transformations of the nineteenth century, a period characterized by the intense transatlantic circuit between America and Africa.
\end{abstract}

Keywords: Slavery Disease. History of Health and Diseases. Dracunculiasis. Guinea Worm. Scientific Collections. 


\section{O Verme da Guiné}

O Dracunculus medinensis é um verme nematoide capaz de infectar as pessoas através do contato com a água contaminada. Ele vive dentro do organismo humano de forma assintomática e não é capaz de causar a morte do indivíduo infectado. A princípio, sua presença no organismo humano é identificada através de bolhas nos pés e pernas do portador, que se rompem quando o verme sai pela pele, o que também provoca a sensação de queimação.

De acordo com os estudos de Mário Augusto P. de Moraes em trabalho sobre dermatoses provocada por helmintos, o ciclo reprodutivo do dracúnculo consiste na contaminação dos crustáceos que habitam lagoas, os copépodes, com as larvas eliminadas pela fêmea, que se desenvolvem em dez dias na água. Após, as mesmas adentrariam no organismo humano por meio da ingestão do líquido contaminado, e levaria cerca de um ano para atingir a fase adulta e reprodutiva:

Os Cyclops são digeridos no estômago e duodeno, e as larvas, agora livres, penetram na parede do intestino e migram através dos linfáticos para o tecido subcutâneo onde evoluem para adultos. Durante o período de migração, pode haver eritema e urticária, acompanhados de febre, prurido intenso, náuseas e vômitos. Uma vez instalada no tecido subcutâneo, a fêmea grávida, que chega a atingir até 1 metro ou mais de comprimento, por 1 ou $2 \mathrm{~mm}$ de diâmetro, introduz sua cabeça na derme, em busca do exterior, e determina nesse ponto o aparecimento de uma pápula avermelhada cujo centro se transforma posteriormente numa bolha. A lesão é encontrada, com mais frequência, entre os ossos do metatarso ou no tornozelo.

Quando a bolha arrebenta, dando saída a um líquido amarelado e estéril, o verme insinua a cabeça na abertura, pronto para descarregar as larvas. (...) ${ }^{1}$

Após o acasalamento, as fêmeas saem do abdômen e percorrem os tecidos sob a pele, geralmente até a parte inferior das pernas ou os pés, e ali formam uma bolha. A bolha causa desconforto com ardor intenso e acaba por romper-se. Quando os atingidos mergulham os pés e pernas nos lagos, na tentativa de aliviar esta dor, a fêmea fecundada libera as larvas e uma vez na água, elas encontram e infectam os copépodes. Com a morte do verme, o mesmo se calcifica e forma um abscesso no local da ferida. E assim se completa seu ciclo.

O tratamento empregado nas zonas endêmicas é o mesmo desde os primeiros registros sobre sua incidência: prendem sua extremidade emergente em um pequeno bastão de madeira

1 MORAES, Mário Augusto Pinto de. 'Dermatoses por helmintos', In ARS Cvrandi, v. 7, n. 6, set. 1974, p. 120. 
e nele vão enrolando o verme com cuidado para não rompê-lo, cerca de 2 ou $3 \mathrm{~cm}$ por dia, até sua completa remoção. O processo levaria ao todo cerca de três semanas. ${ }^{2}$

Figura 1 - Ciclo de vida do Dracunculus medinensis

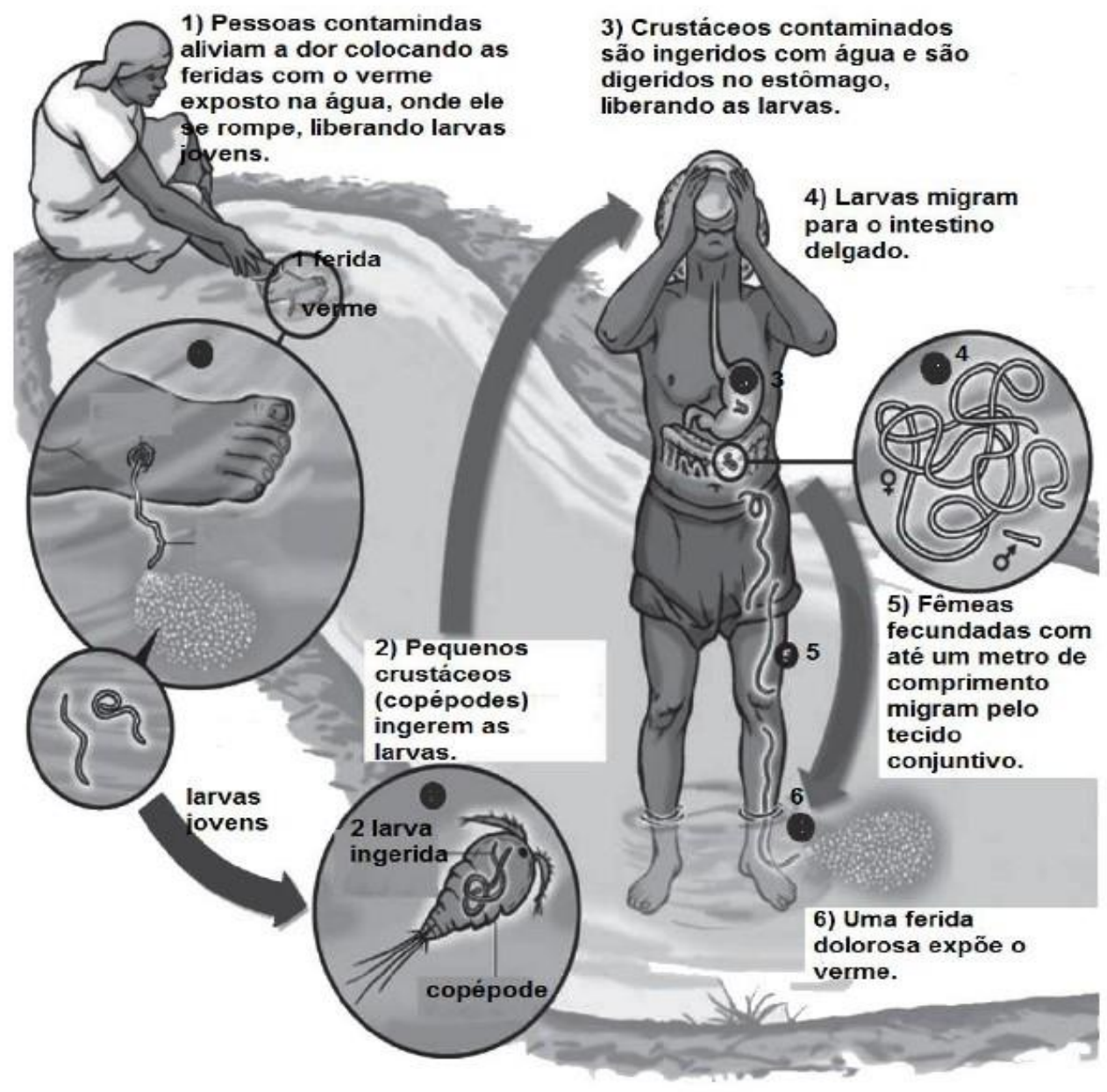

Fonte: www.cartercenter.org. Acesso em: 20 jan. 2021. (Adaptado)

Devido à sua tradicional forma de extração, alguns estudos sobre a História da Medicina, atribuem ao bastão com a serpente no seu entorno que figura no símbolo da medicina, comumente atribuído a Asclépio, deus da medicina cultuado na Grécia antiga, sendo na verdade baseada na figura do dracúnculo enrolado em um bastão. "O símbolo da medicina seria uma simples publicidade do médico anunciando sua habilidade em extrair um parasito subcutâneo". ${ }^{3}$

\footnotetext{
2 MORAES, Mário Augusto Pinto de. Op. cit., p. 120.

3 REZENDE. Joffre Marcondes de. 'O símbolo da medicina e o verme da Guiné', In: Brasília Med. $2012 ; 49$ (1), p. 76-78.
} 
Figura 2 - Extração do Dracunculus medinensis

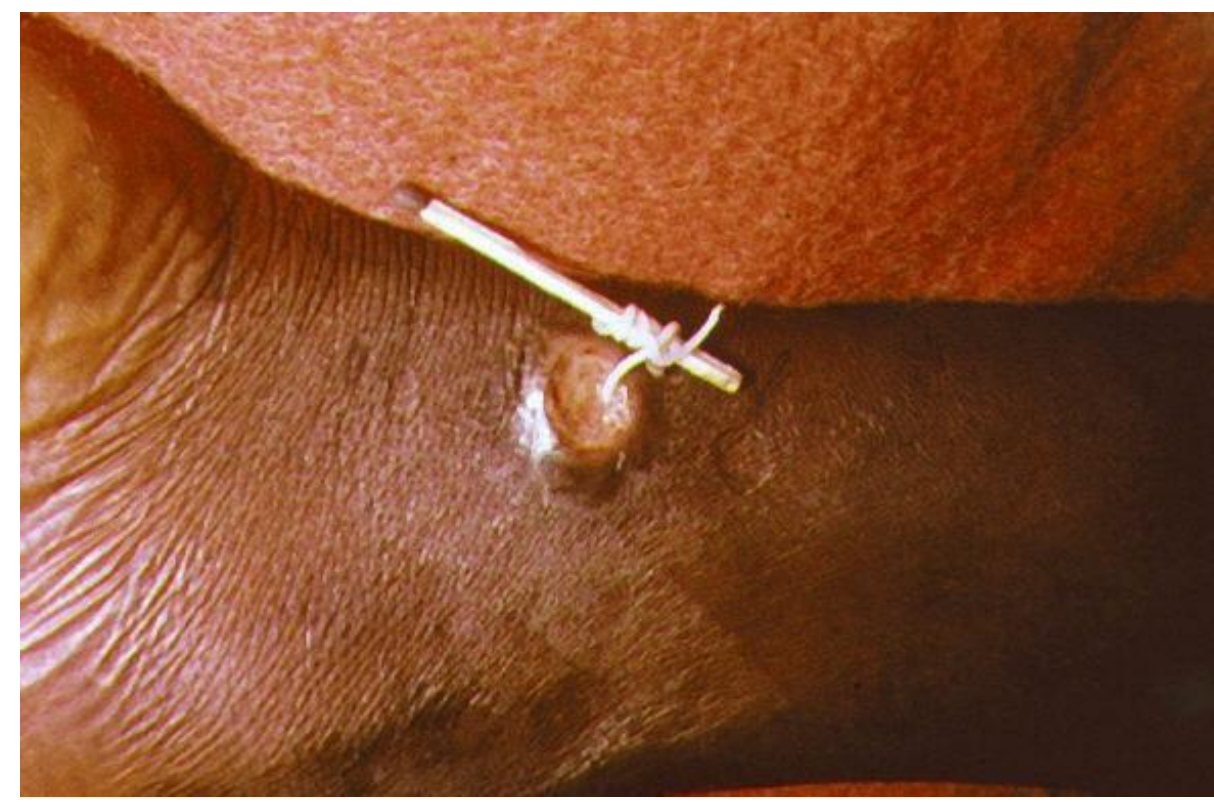

Fonte: www.cartercenter.org. Acesso em: 20 jan. 2021.

Trata-se de um helminto comum, principalmente entre os povos que habitam o Oriente Médio e África. A ausência do hospedeiro intermediário, os copépodes, impediu que a espécie completasse seu ciclo reprodutivo e se espalhasse pelo continente americano. Contudo, devido ao tráfico atlântico, inúmeros portadores da dracunculose foram trazidos para o território brasileiro, o que possibilitou seu registro em algumas regiões do Brasil e América Latina até as primeiras décadas do século XX, tal como a amostra que faz parte da Coleção de Helmintologia do Instituto Oswaldo Cruz (CHIOC).

Para iniciar uma discussão sobre a importância do verme da guiné para o estudo da história das ciências no Brasil, é válido salientar algumas das características do processo de interação entre o parasita e o organismo humano e seus principais registros históricos no Brasil.

\section{A Coleção de Helmintologia do IOC}

A institucionalização da helmintologia como campo autônomo emergiu no século XIX, com a redefinição da autoridade científica da clínica posta pelo laboratório e das regras de produção de conhecimento, além da emergência de novos fatos até então desconhecidos pela comunidade médica, tais como a existência do hospedeiro intermediário, das gerações alternadas e do ciclo de vida do parasita, que se agregaram a novos conhecimentos sobre a causalidade de certas doenças. ${ }^{4}$

\footnotetext{
${ }^{4}$ EDLER, Flavio Coelho. A Medicina no Brasil Imperial: climas, parasitas e patologia tropical. Rio de Janeiro: Editora FIOCRUZ, 2011, p. 123-134.
} 
No Brasil, as primeiras pesquisas em parasitologia médica foram desenvolvidas a partir de 1860, contexto em que se configurava um processo de institucionalização marcado por inúmeras controvérsias e disputas "justamente quando começou a empregar ferramentas conceituais próprias para investigar doenças que faziam parte do patrimônio científico de grupos bem consolidados no território médico, reconstruindo sua etiologia, diagnóstico e tratamento". ${ }^{5}$

Nesse sentido, é importante destacar o protagonismo de instituições que são de grande relevância para a gênese da Medicina Tropical durante o século XIX, como a Academia Imperial de Medicina, que detinha o monopólio do controle e validação do saber médico na corte e a Escola Tropicalista Baiana, constituída inicialmente fora do ambiente institucional. Particularmente, esta última foi composta por um grupo de médicos baianos, que se reuniam em torno da Gazeta Médica da Bahia (1866-1915) e ajudaram a "disseminar 'novas idéias sobre saúde e doença no Brasil'. A Escola Tropicalista Baiana, como tal grupo ficou conhecido, notabilizou-se por seus trabalhos sobre beribéri, ancilostomíase, filariose e ainhum - doenças associadas ao clima tropical". ${ }^{6}$

Portanto, em 1900, quando foi criado o Instituto Soroterápico Federal em Manguinhos, que em 1908 mudaria de nome para Instituto Oswaldo Cruz (IOC), o Brasil já tinha importantes contribuições no campo da helmintologia, com destaque para os trabalhos realizados por Adolpho Lutz. ${ }^{7}$ Ao ingressar no IOC, Lutz já tinha mais de 50 anos e era um profissional experiente, tendo atuado em diversas áreas da medicina em instituições no Brasil e no exterior, com destaque para o Instituto Bacteriológico de São Paulo, onde esteve à frente no período entre 1893 a $1908 .^{8}$

Em 1917, ao percorrer o Nordeste estudando o Schistosoma mansoni e a esquistossomose, abordando a sua distribuição geográfica, sua incidência e ampliou sua contribuição à malacologia e helmintologia ao determinar de forma pioneira as espécies de hospedeiros intermediários no Brasil. Lutz deu importantes contribuições para o estudo sobre a ancilostomose, a ascaridíase, o oxiurus e da solitária humana entre outros vermes

A história do Laboratório de Helmintos e Parasitos de Vertebrados e da CHIOC se confunde, já que foram criados em 1913, por José Gomes de Faria, ${ }^{9}$ como resultado de seu

\footnotetext{
${ }^{5}$ EDLER, Flavio Coelho. Pesquisa clínica e experimental no Brasil oitocentista: circulação e controle do conhecimento em helmintologia médica, In História, Ciências, Saúde - Manguinhos, Rio de Janeiro, v.17, n.3, jul.-set. 2010, p.751.

${ }^{6}$ EDLER, Flavio Coelho. A Escola Tropicalista Baiana: um mito de origem da medicina Tropical no Brasil, In História, Ciências, Saúde - Manguinhos, Rio de Janeiro, vol. 9(2):357-85, maio-ago. 2002, p. 361.

${ }_{7}^{7}$ Adolpho Lutz (18.12.1855 - 06.10.1940). Médico e cientista brasileiro, graduou-se em Medicina em Berna na Suíça (1879), onde também concluiu seu doutorado (1880), Lutz começou a clinicar em Limeira, São Paulo. Atuou no Instituto Bacteriológico de São Paulo (1893), onde permaneceu até se mudar para o Instituto Oswaldo Cruz (1908), onde trabalhou por 32 anos. Informações disponíveis em: http://www.ioc.fiocruz.br/pages/personalidades/AdolphoLutz.htm.

8 BENCHIMOL, Jaime. Adolpho Lutz: um esboço biográfico. História, Ciências, Saúde - Manguinhos, vol. 10(1): 13-83, jan.-abr. 2003, p.7.

9 José Gomes de Faria (20.05.1887 - 09.08.1962). Formado em medicina pela Faculdade Nacional de Medicina (1908). Admitido no Instituto Soroterápico Federal por Oswaldo Cruz (1906). Organizou no Instituto o primeiro serviço de atendimento para casos de helmintos (1909), que mais tarde se tornaria o
} 
interesse pela pesquisa nesta área. Este pesquisador era profundamente dedicado ao estudo de helmintos e, por esta razão, foi escolhido para chefiar o laboratório, onde permaneceu por apenas dois anos, de 1913 a 1915. As primeiras amostras do acervo inicial da coleção foram "resultado do trabalho de campo de Gomes de Faria que, já trabalhando no Instituto desde 1907, coletava helmintos e os conservava como coleção particular". ${ }^{10}$ Após sua saída, foi substituído por Lauro Pereira Travassos ${ }^{11}$ que já atuava no Instituto Oswaldo Cruz como pesquisador desde 1913, em parceria com Gomes de Faria. ${ }^{12}$

Nas primeiras décadas do século XX, o IOC obteve grande destaque entre as instituições de pesquisa nas áreas da Medicina e Saúde Pública no Brasil. Nancy Stepan ${ }^{13}$ e Jaime Benchimol ${ }^{14}$ chamam a atenção de que a instituição representou um marco na produção do conhecimento científico no Brasil -- por meio das pesquisas em laboratórios e da difusão da medicina moderna. Seus renomados cientistas não se restringiam a consumir e adaptar ideias advindas da Europa no território brasileiro, tornando-se produtores de conhecimento original em suas respectivas áreas de atuação. Uma das razões seria o fato das pesquisas desenvolvidas no IOC estarem voltadas para a solução dos problemas de saúde pública específicos de cada uma das regiões do país, que se tornaram conhecidas através das expedições de combate a endemias que grassavam o Brasil adentro. Assim, encontraram soluções dotadas de originalidade, voltadas para a especificidade e necessidades de um país situado nos trópicos.

Assim, quando o Laboratório de Helmintos e sua coleção foram criados, o IOC já era considerado a maior instituição de pesquisa científica no Brasil, cujo modelo institucional estava alicerçado nas ações de ensino, produção e pesquisa científica. Além da formação de quadros profissionais, produzia soros e vacinas e realizava pesquisa básica e aplicada. Tudo isso, acrescido à autonomia financeira que alcançou no período, garantiu-lhe a sobrevivência ao longo das diversas fases da história do Brasil republicano.

Laboratório de Helmintologia e da Coleção de Helmintos (1913). Permaneceu no instituto até 04.10.1944. Informações disponíveis em: http://www.ioc.fiocruz.br/pages/personalidades/JoseGomesDeFaria.htm

10 NORONHA, Dely. 'Coleção Helmintológica do Instituto Oswaldo Cruz (CHIOC)', In: I Simpósio Nacional de Coleções Científicas: Evento comemorativo aos 105 anos do Instituto Oswaldo Cruz. Rio de Janeiro: IOC. FioCruz, 2005, p. 51.

11 Lauro Pereira Travassos (02.07.1890 - 20.11.1970). Formado em Medicina pela Faculdade de Medicina do Rio de Janeiro (1913). Ainda estudante, foi um dos primeiros discípulos de Oswaldo Cruz no Instituto Soroterápico Federal. Assumiu o comando do Departamento de Helmintologia e a Curadoria da Coleção Helmintológica (1926). Lecionou em diversas faculdades como a Faculdade de Medicina de São Paulo, no Tropen Institut em Hamburgo, na Escola Nacional de Veterinária, hoje UFRRJ e participou da criação da Universidade do Distrito Federal, hoje UERJ.Informações disponíveis em: http://www.ioc.fiocruz.br/pages/personalidades/LauroPereiraTravassos.htm.

12 COURA, José Rodrigues et al (Orgs.). Centenário de Oswaldo Cruz: 1900-2000. Rio de Janeiro: memórias do Instituto Oswaldo Cruz, 2000, p. 607-614.

13 STEPAN, Nancy. Gênese e evolução da ciência brasileira: Oswaldo Cruz e a política de investigação científica e médica. Rio de Janeiro: Editora Artenova s.a, 1976.

${ }^{14}$ BENCHIMOL, Jaime L (Coord.). Manguinhos, do sonho à vida: A ciência na Belle Époque. Rio de Janeiro: Casa de Oswaldo Cruz, 1990. 
De acordo com Noronha et al, ${ }^{15}$ a coleção foi adquirindo novos exemplares ao longo dos anos por meio das pesquisas dos cientistas de Manguinhos, como o próprio Oswaldo Cruz. Ao realizarem as campanhas contra as endemias no Brasil, os pesquisadores aproveitavam a oportunidade para coletar exemplares que mais tarde comporiam seu acervo. A intensa coleta de amostras integravam suas atividades das pesquisas de campo, que ainda incluíam a descrição de novas espécies e troca de informações com seus pares, com o intuito de ampliar o conhecimento naquela área específica.

Some-se a isto, a incorporação de exemplares de coleções particulares e institucionais, ainda na primeira metade do século XX:

\begin{abstract}
A maior expansão da coleção se deu, primeiro, através da obtenção de material de helmintologia coletado durante as grandes expedições realizadas por Travassos e seus colaboradores às diferentes regiões do Brasil e, depois, pela continuação dessas atividades por parte de diversos pesquisadores, que vêm investigando a ocorrência de helmintos parasitos de animais terrestres e marinhos de nossa fauna. Outro procedimento para ampliar o acervo de helmintologia está relacionado às incorporações de coleções institucionais, como as do Museu Paulista (588 amostras) no período de 1878 a 1909, do Instituto Pasteur de São Paulo (17 amostras), obtidas no período de 1898 a 1915, do Instituto Bacteriológico de São Paulo (33 amostras), do Instituto Butantã (102 amostras) entre 1912 e 1938 e do Instituto Biológico de São Paulo (8 amostras), de 1929 a 1931. Das coleções particulares, a primeira a ser incorporada foi a de Pedro Severiano Magalhães, pertencente à Escola Bahiana de Medicina, importante centro de estudos de helmintologia no Brasil durante os séculos 1878 a 1915. Os principais tipos dessa coleção encontram-se na Alemanha, Áustria e Suíça, principalmente os cestóides. ${ }^{16}$
\end{abstract}

É importante destacar que as lâminas mais antigas da Coleção Helmintológica faziam parte da coleção particular de Pedro Severiano Magalhães, ${ }^{17}$ que foi doada ao IOC e possui amostras do século XIX; com a incorporação da Coleção Adolpho Lutz à CHIOC, que até então se restringia a helmintos, passou a ser uma coleção parasitológica, já que não foi feita uma numeração à parte ou separação de um material diferente dos vermes. Este dado é importante de ressaltar, pois manteve a unidade e a organização original da coleção. ${ }^{18}$

E entre as amostras de grande relevância para a coleção está a do Dracunculus medinensis, coletada por Oswaldo Cruz no Brasil.

\footnotetext{
15 NORONHA, Dely et al. Adolpho Lutz e a Coleção de Helmintologia do Instituto Oswaldo Cruz. Rio de Janeiro: Museu Nacional, 2009.

${ }^{16}$ Ibidem, p. 22-23.

17 Para saber mais informações, ler:LENT, Herman; FREITAS, J. F. Teixeira de. Alguns helminthos da collecção de Pedro Severiano de Magalhães. Mem. Inst. Oswaldo Cruz, Rio de Janeiro , v. 32, n. 2, p. 305309, 1937 .

18 NORONHA, Dely. 'Coleção Helmintológica...Op. cit., p.51.
} 
Figura 3 - Ficha do Dracunculus medinensis N. 8285, coletada por Oswaldo Cruz.

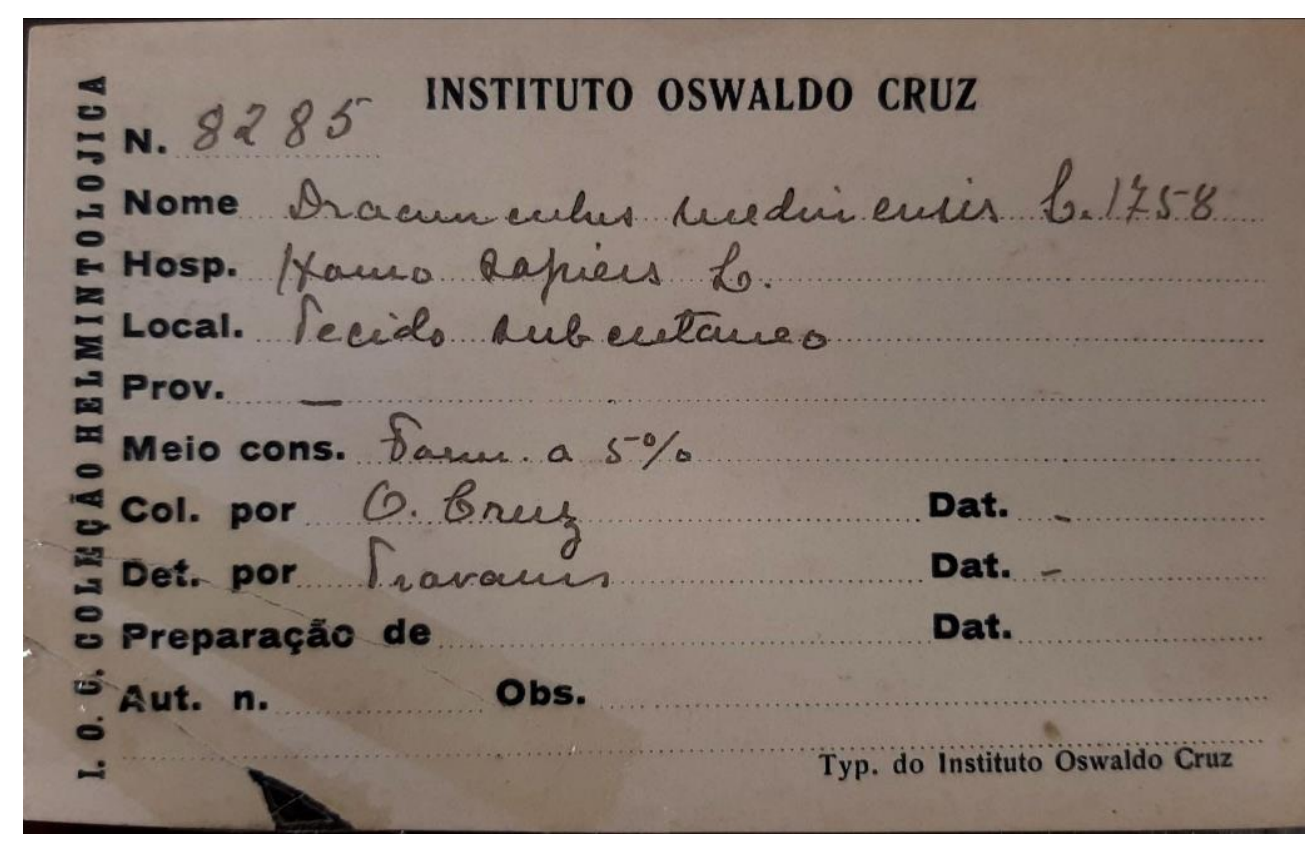

Fonte: Acervo da CHIOC.

Conforme se depreende da leitura da ficha, não se pode extrair muitas informações sobre o sítio de infecção, proveniência, data da coleta ou as circunstâncias envolvidas. Dely Noronha chama a atenção, para a exiguidade de informações dos primeiros exemplares da coleção, provenientes das campanhas e expedições pelo interior do Brasil:

Pesquisadores do Instituto Soroterápico em campanhas contra as endemias no Brasil (febre amarela, peste bubônica e varíola), além de tratar a população doente, aproveitavam a ocasião para investigar os animais domésticos e silvestres da fauna brasileira. Quando regressaram ao instituto, o material parasitário coletado era entregue aos diferentes cientistas, de acordo com a sua especialidade. Na CHIOC temos amostras de nematóides coletados durante necropsias em aves da Região Amazônica por Oswaldo Cruz em 1910, quando a campanha sanitária para impulsionar a construção da Estrada de Ferro MadeiraMamoré. Carlos Chagas, Magarino Torres e Nery Guimarães, entre outros pesquisadores, também contribuíram para ampliar a CHIOC. ${ }^{19}$

A partir de tais constatações, é possível concluir que a amostra do dracúnculo que integra a CHIOC foi obtida em uma das expedições empreendidas por Oswaldo Cruz, na primeira metade do século XX e extraída do tecido subcutâneo de um homem ou uma mulher da África, que provavelmente chegou ao Brasil através do tráfico na segunda metade do século XIX. Ainda que o tema seja pouco pesquisado, existem registros sobre a existência de focos desta doença que infestava os escravos em algumas regiões do Brasil, como o relatado por René Rachou, ${ }^{20} \mathrm{em}$ Feira de Santana, na Bahia:

\footnotetext{
19 NORONHA, Dely et al. Adolpho Lutz e a Coleção... Op. cit, p. 22.

20 René Guimarães Rachou (30.06.1963 - 21.11.1963). Formou-se em Medicina pela Faculdade Nacional de Medicina da Universidade do Brasil (1939) e em Assistência Social pela Universidade do Brasil (1940). Ingressou no Serviço de Profilaxia da Malária no estado de São Paulo, onde fez o Curso de Malária pelo
} 
A dracunculose é encontrada na África e na Ásia, mas já houve um foco da doença no Brasil, na localidade de Feira de Santana, Bahia, que hoje está completamente extinta. Foi introduzida por escravos africanos e era conhecida por "bicho da costa". Segundo Rachou, "o desaparecimento espontâneo desse foco teve como causa a falta de um bom hospedeiro intermediário na região ou, então, de condições favoráveis ao seu desenvolvimento. ${ }^{21}$

Embora não informe a data em que este foco endêmico ocorreu na Bahia, provavelmente a informação foi extraída do artigo "A Filaria de medina transportada para a America por negros D'Africa; provas de sua endemicidade na província da Bahia, e da introdução no corpo humano pelo Estômago" (1877), publicado na Gazeta Médica da Bahia pelo Dr. Manoel Victorino Pereira, 22 como parte de sua tese. ${ }^{23}$ Neste estudo, o autor menciona a existência de um foco endêmico em Feira de Santana e seus arredores em 1849, e defendia acertadamente que a sua infestação nas pessoas seria através da água contaminada.

Por ser uma doença originária da África cujo hospedeiro intermediário, o copépode, não existe no Brasil, os casos identificados deste lado do Atlântico, só foram possíveis como resultado do intenso tráfico negreiro, uma vez que cerca de 10 milhões e meio de negros africanos desembarcaram aqui para abastecer o mercado de escravos no Brasil e nas Américas. ${ }^{24}$

\section{Doenças e escravidão no Brasil}

Trabalhos com temáticas sobre doenças, mortalidade e práticas de cura de escravos, despontaram nos últimos anos como de grande relevância para a história da saúde dessas populações. Isto não seria possível sem estudos interdisciplinares que permitem um maior diálogo entre pesquisas que contemplam a escravidão e a História da Medicina, de autores como

Departamento Nacional de Saúde do Rio de Janeiro (1942). Teve passagens por importantes pelo Serviço Nacional de Malária (1943), o Laboratório Nacional de Malária (SNM) e foi um dos idealizadores da Escola de Entomologia daquele órgão. Fundou a Revista Brasileira de Malariologia (1949) e foi Diretor do Instituto de Malariologia (1955), que após o seu falecimento passou a se chamar Centro de Pesquisas René Rachou (Fiocruz-MG)

21 RACHOU, René Guimarães. 'Distribuição geográfica das filarioses humanas no Brasil', In. Revista Brasileira de Malariologia e Doenças Tropicais, v.9, n.1, jan. 1957, p. 79.

22 Manuel Vitorino Pereira (30.01.1853 - 9.11.1902). Formou-se médico pela Faculdade de Medicina da Bahia (1876). Aos 25 anos, tornou-se catedrático de medicina legal e em 1883 foi aprovado em concurso para professor de clínica cirúrgica, conquistando sua segunda cátedra na Faculdade de Medicina. Adepto das idéias abolicionistas, entrou no Partido Liberal na Bahia. Assumiu o governo da Bahia após a Proclamação da República, foi senador estadual e vice-presidente do Brasil no governo de Prudente de Moraes. Fonte: Dicionário Histórico-biográfico Brasileiro - DHBB. Capturado em 25. Jan. 2021. Online. Disponível na Internet: http://cpdoc.fgv.br/sites/default/files/verbetes/primeirarepublica/VITORINO,\%20Manuel.pdf.

${ }^{23}$ PEREIRA, Manoel Victorino. Moléstias parasitárias mais frequentes nos climas tropicaes. These inaugural. Bahia: 1876.

24 Informação disponível em The Transatlantic Slave Trade Database. Capturado em 25. jan. 2021. Online. Disponível na Internet: https://www.slavevoyages.org/assessment/estimates. De acordo com o banco de dados do site, o número de desembarcados no Brasil e América Latina seria de 10.702.656 escravos; 
Mary C. Karasch, ${ }^{25}$ Diana Maul de Carvalho, ${ }^{26}$ Márcia Amantino ${ }^{27}$ e Betânia Gonçalves Figueiredo. 28

Karasch relata as doenças que mais acometiam os escravos no Rio de Janeiro na primeira metade do século XIX. Em sua narrativa, afirma que era muito comum que estes fossem acometidos por parasitas como lombrigas, solitárias, ancilóstomos e dracunculos, sendo este último, popularmente conhecido como verme da costa ou da guiné, e era muito comum entre os escravos. ${ }^{29}$

Contudo, no Brasil, a historiografia carece de estudos específicos sobre vermes e parasitas introduzidos no continente americano pelo tráfico de escravos. Somente a nota de pesquisa de Sá e Maia-Herzog (2003), pode ser considerado um trabalho sobre esta temática. Ali, as autoras investigam aspectos históricos da introdução e disseminação da oncocercose no Brasil, uma doença causada por verme parasita, o Onchocerca, oriundo do continente africano, que tem como vetor o mosquito borrachudo e pode causar cegueira nas pessoas. Nesta nota, elas chamam a atenção para a introdução de doenças como a esquistossomose no Brasil e América Latina por meio do tráfico de escravos.

Contudo, é possível encontrar publicações como o livro escrito pelo médico Octávio de Freitas, "Doenças Africanas no Brasil" (1935), que se baseia em farta bibliografia produzida por viajantes, manuais, publicações e teses médicas, para elaborar uma lista de doenças atribuídas aos africanos: "maculo", "bouba", "cundu", "frialdade", "bicho da costa", "ainhum", "bicho dos pés", "desinteria mansoniana", "alastrim", "filárias" e "mosquitos africanos".

Lima, ${ }^{30}$ em sua tese de doutorado em História, chama atenção para o momento em que o livro de Freitas (1935) foi elaborado, quando inúmeras teorias raciais estavam sendo produzidas para explicar o atraso brasileiro frente às nações europeias. Segundo Lima, por este motivo, Freitas apresenta uma perspectiva racializada a respeito do "o mal que o colono africano introduziu em nosso país"31:

Podemos perceber uma clara conotação racial na abordagem sobre as doenças africanas feita por Otávio de Freitas quando usa categorias geográficas e raciais

\footnotetext{
${ }^{25}$ KARASCH, Mary C. A vida dos escravos no Rio de Janeiro (1808-1950). São Paulo: Companhia das Letras, 2000.

26 CARVALHO, Diana Maul de. 'Doenças dos escravizados, doenças africanas?', In PORTO, Ângela (org.). Doenças e escravidão: sistema de saúde e práticas terapêuticas. Rio de Janeiro: Casa de Oswaldo Cruz/Fiocruz, 2007. CD-ROM.

27 AMANTINO, Márcia. 'As condições físicas e de saúde dos escravos fugitivos anunciados no Jornal do Commercio (RJ) em 1850', In: História, Ciências, Saúde - Manguinhos, v. 14, n. 4, p.1377-1399, dez 2007. 28 FIGUEIREDO, Betânia Gonçalves. 'As doenças dos escravos: um campo de estudo para a história das ciências da saúde', In: Uma história brasileira das doenças. Rio de Janeiro: Mauad X, 2006, p. 252-274.

${ }^{29} \mathrm{KARASCH}$, Mary C. A vida dos escravos... Op. cit., 239-240.

30 LIMA, Silvio Cezar de Souza. O corpo escravo como objeto das práticas médicas no Rio de Janeiro (18301850). Tese (Doutorado em História das Ciências e da Saúde) - Fundação Oswaldo Cruz. Casa de Oswaldo Cruz, 2011.

31 FREITAS, Octavio de. Doenças africanas no Brasil. São Paulo: Cia Ed. Nacional. 1935, p. 30.
} 
como "Vermes do continente branco" e "vermes do continente negro"; quando constrói a idéia de que uma patologia age de forma diferente nos negros e ainda quando avalia que os parasitas do "continente negro" seriam mais agressivos e mais perigosos. Para além dos julgamentos da racialização das doenças, a visão que o autor produz sobre a África é de um continente produtor de doenças. Os africanos são apresentados antes como o transporte dos males do que como doentes, sempre os "portadores das doenças". Uma maneira de entender o papel dos africanos no livro é justamente o de tratá-los como se fossem vetores e hospedeiros da doença. ${ }^{32}$

Questões como moradias insalubres, má alimentação, castigos físicos e jornada de trabalho extensas e exaustivas, não são apresentadas pelo autor como fatores que poderiam afetar a saúde e a mortalidade dos escravos. No entanto, o "verme da costa", nome pelo qual o dracúnculo também era popularmente conhecido, "que os pretos Minas costumavam denominar, não sei porque motivo, "subiá", era o nome conhecidíssimo e quase pré-histórico do nematóide - o dracúnculo -, pequena "serpente de fogo (...)",33 há um capítulo dedicado à sua ocorrência entre os escravos, com relatos sobre sua origem, etiologia, conjunto de sintomas e profilaxia.

As informações levantadas no capítulo dedicado à dracunculose, demonstram que sua ocorrência entre os escravos era comum. Embora sua existência conste nos livros e manuais médicos, seu registro na documentação médica produzida em hospitais ou outros espaços de tratamento dos cativos da época, é raro. Embora não fosse letal, debilitava seus portadores e isto chamava a atenção dos médicos com a doença. Porém, deve-se atentar que estava igualmente em risco a dinâmica da produção, já que os afetados pela doença certamente não trabalhavam com a mesma qualidade que os sãos.

Pode-se supor que a existência de poucos registros de sua ocorrência nas Santas Casas de Misericórdias seria porque a maioria dos africanos, familiarizados com a existência do verme, faziam sua própria extração ou confiavam o seu tratamento a curandeiros, ou até mesmo o fato de que os proprietários não gastariam muito para preservar os escravos atingidos com a doença. Isto pode ajudar a explicar dois dados: a exiguidade dos registros médicos sobre o verme e as poucas propostas no sentido de atender e tratar os escravos atingidos por ela, que não chegavam a ser implementadas. Em nenhuma das obras e manuais médicos produzidos naquele período, "sugere a criação de um serviço destinado ao tratamento médico de escravos. Assim, observase, na literatura coeva à escravidão, a inexistência de uma preocupação com a prática médica voltada para a força de trabalho escrava". ${ }^{34}$ De acordo com Porto, ${ }^{35}$ a saúde do negro só seria alvo de cuidados mais efetivos pelo seu senhor, a partir da segunda metade do século XIX, quando há a proibição do tráfico transatlântico e a consequente diminuição da oferta de escravos no mercado, que o torna um bem mais caro.

\footnotetext{
32 LIMA, Silvio Cezar de Souza. O corpo escravo como objeto... Op. cit., p.23.

33 FREITAS, Octavio de. Doenças africanas no Brasil... Op. cit., p. 115.

34 PORTO, Ângela. 'O sistema de saúde do escravo no Brasil do século XIX: doenças, instituições e práticas terapêuticas', In. História, ciências, saúde - Manguinhos, Rio de Janeiro , v. 13, n. 4, Dec. 2006, p. 1021.

35 Idem.
} 
Segundo Freitas, no que tange à dracunculose, no século XIX já "não haveria controvérsia sobre a sua origem africana":

A verdadeira pátria do bicho da costa, cuja história, hábitos e distúrbios patológicos, como nosso oportuníssimo hóspede, eu pretendo contar, é a África. Alí ele é encontrado em abundância, tanto na costa ocidental entre o Ecuador e o imite norte do Senegal -, como no interior do continente negro, onde focos inúmeros podem ser apontados em várias localidades do Sudão.

Daí as denominações pelas quais é assinalado: Filária da Medina, Filária da Guiné, Bicho da Costa. ${ }^{36}$

Os manuais de medicina do século XIX, que serviam de divulgadores do saber médico para uma sociedade que tinha pouco acesso a profissionais da saúde, seja pela distância dos grandes centros urbanos ou porque eram poucos os que atuavam em determinada região, mencionam a dracunculose como uma doença que afetava os cativos. Sigaud, ${ }^{37}$ publicado originalmente em 1844, em Paris, afirma ter se deparado com quatro casos do "Verme da Guiné" no Brasil. Chernoviz (1890) ${ }^{38}$ defendia que o "Verme da Costa", assim chamados "porque nos primeiros tempos eram os pretos recém-chegados da África que apareciam com este verme: mas presentemente observa-se em muitos lugares do Brasil, como outros muitos vermes, desenvolve-se espontaneamente no corpo do homem"39 e relata tê-lo encontrado apenas duas vezes em 1848, em escravos recém-chegados no Rio de Janeiro. ${ }^{40}$

\section{Considerações Finais}

A CHIOC é a maior do gênero da América do Sul e uma das maiores no mundo. Pela história e particularidade de seus exemplares, é uma importante fonte de pesquisa para a História da Ciência no Brasil. Seu ineditismo está no fato de possuir helmintos raros, que estão presentes nos distintos biomas do Brasil, nos cinco continentes e em vias de extinção, além de ter abrigado acervos formados por instituições como o Butantã, Museu Paulista e Instituto Pasteur, e amostras de coleções particulares e de importantes pesquisas.

Este artigo não pretende esgotar sua história, mas chamar a atenção para a preciosidade das fontes que constituem a Coleção, sobretudo no que se refere ao seu aspecto histórico e por

\footnotetext{
36 FREITAS, Octavio de. Doenças africanas no Brasil... Op. cit., p. 116.

37 SIGAUD, Joseph François Xavier. Do clima e das doenças do Brasil ou estatística médica deste Império. Rio de Janeiro: Fiocruz, 2009.

38 CHERNOVIZ, Pedro Luiz Napoleão. Dicionário de medicina popular. v.1. Paris: A. Roger et F. Chernoviz. 1890.

39 De acordo com o historiador Flávio C. Edler, somente após a década de 1850 a comunidade médica deixou de defender a tese da geração espontânea dos helmintos. Até então se desconhecia o conceito de hospedeiro intermediário e da causalidade patogênica entre alguns vermes e seus hospedeiros. Cf. EDLER, Flávio Coelho. A Medicina no Brasil Imperial... Op. cit.
}

40 CHERNOVIZ, Pedro Luiz Napoleão. Op. cit., p. 881-883. 
fornecer elementos que estabelecem um importante diálogo com a História da Medicina e das Doenças. O exemplo trazido com a mostra do Dracunculum medinensis, também conhecido como verme da costa ou da Guiné, coletado por Oswaldo Cruz em uma de suas expedições pelo interior do Brasil no início do século XX, demonstra seu potencial ainda pouco explorado pela produção historiográfica recente.

Vale ressaltar que o avanço dos negócios transoceânicos, incluindo o tráfico de africanos escravizados e um intenso fluxo de mercadorias, revela uma dinâmica complexa das condições de saúde dos indivíduos embarcados nos negreiros, livres e escravos.

Sobre o impacto do tráfico transatlântico na mortalidade escrava no Brasil, Barbosa ${ }^{41}$ chama atenção para considerarmos outras variáveis com o intuito de compreender a dinâmica entre a doença e a morte em uma sociedade escravista, tais como aspectos ambientais, condições sanitárias, regimes de trabalho, dietas alimentares, vestuário etc. Dessa forma, "na medida em que campos de estudos da história da medicina e da história das doenças se aproximam, surgem importantes abordagens com possibilidades de sistematização a respeito da história das doenças dos cativos". 42

Nesse sentido, a ênfase na discussão em torno da dracunculose e das dinâmicas científicas relacionadas a ela, esboça um caminho analítico promissor para as pesquisas sobre história da saúde de indivíduos que percorriam os caminhos e entrepostos do tráfico de africanos no mundo atlântico. Além disso, ajuda a compreender outro ângulo da saúde dos cativos: o da existência de um verme oriundo da África que, embora não fosse letal, debilitava seus portadores e comprometia sua produtividade.

Um estudo mais aprofundado da bibliografia pertinente ao tema, demonstra que a dracunculose era bastante comum entre escravos e consta nos principais manuais de medicina do século XIX. Mais do que uma doença de escravo, é uma doença de origem africana, o que aumenta sua relevância, uma vez que este tema ainda não recebeu a merecida atenção pela historiografia da História da Medicina e das Doenças no Brasil.

Este trabalho procura contribuir para o avanço das discussões neste campo, bem como no debate sobre o uso de exemplares de coleções científicas, que não se restringem a locais de memória ou de preservação de arquivos e objetos que estão sob sua guarda. As Coleções também possuem informações importantes e são fontes de pesquisa para a história das ciências e dos objetos que, neste caso, é uma espécie. Testemunha não apenas de agendas de investigação científica, conforme demonstrado por Domingues e Sá ${ }^{33}$ e Lopes e Heizer, ${ }^{44}$ como

\footnotetext{
41 BARBOSA, Keith Valéria de Oliveira. Doença e cativeiro: um estudo sobre a mortalidade e sociabilidades escravas no Rio de Janeiro, 1809-1831. Curitiba:CRV, 2020.

42 Ibidem, p. 26.

43 DOMINGUES, Heloisa Bertol e SA, Magali Romero. 'Expedições Científicas e Colecionismo: dois exemplos no Brasil-Século XX', In. Asclepio, 71(2), 2019, p.272.

44 LOPES, Maria Margaret; HEIZER, Alda (Org.). Colecionismo, prática de campo e representações. Campina Grande: EDUEPB, 2011.
} 
também da circulação de patógenos, pessoas e organismos, o Dracunculus medinensis é um registro do tráfico atlântico e das doenças que acometia a população de escravos africanos. 


\section{Referências}

\section{Bibliografia}

AMANTINO, Márcia. 'As condições físicas e de saúde dos escravos fugitivos anunciados no Jornal do Commercio (RJ) em 1850', In: História, Ciências, Saúde - Manguinhos, v. 14, n. 4, p.13771399, dez 2007.

BARBOSA, Keith Valéria de Oliveira. Doença e cativeiro: um estudo sobre a mortalidade e sociabilidades escravas no Rio de Janeiro, 1809-1831. Curitiba:CRV, 2020. 124p.

BENCHIMOL, Jaime L (Coord.). Manguinhos, do sonho à vida: A ciência na Belle Époque. Rio de Janeiro: Casa de Oswaldo Cruz, 1990. 250p.

BENCHIMOL, Jaime L. Adolpho Lutz: um esboço biográfico. História, Ciências, Saúde Manguinhos, vol. 10(1): 13-83, jan.-abr. 2003.

CARVALHO, Diana Maul de. 'Doenças dos escravizados, doenças africanas?', In PORTO, Ângela (org.). Doenças e escravidão: sistema de saúde e práticas terapêuticas. Rio de Janeiro: Casa de Oswaldo Cruz/Fiocruz, 2007. CD-ROM.

CHERNOVIZ, Pedro Luiz Napoleão. Dicionário de medicina popular. v.1. Paris: A. Roger et F. Chernoviz. 1890.

COURA, José Rodrigues et al (Orgs.). Centenário de Oswaldo Cruz: 1900-2000. Rio de Janeiro: memórias do Instituto Oswaldo Cruz, 2000. 720p.

DOMINGUES, Heloisa Bertol e SA, Magali Romero. 'Expedições Científicas e Colecionismo: dois exemplos no Brasil-Século XX', In. Asclepio, 71(2), 2019, p.272.

EUGÊNIO, Alisson. 'Ilustração, escravidão e as condições de saúde dos escravos no Novo Mundo', In: Varia História. v. 25, n. 41, p. 227-244, jan. /jun. 2009.

EDLER, Flavio Coelho. A Escola Tropicalista Baiana: um mito de origem da medicina Tropical no Brasil, In História, Ciências, Saúde - Manguinhos, Rio de Janeiro, vol. 9(2):357-85, maio-ago. 2002.

EDLER, Flavio Coelho. Pesquisa clínica e experimental no Brasil oitocentista: circulação e controle do conhecimento em helmintologia médica, In História, Ciências, Saúde - Manguinhos, Rio de Janeiro, v.17, n.3, jul.-set. 2010, p.739-755

EDLER, Flavio Coelho. A Medicina no Brasil Imperial: climas, parasitas e patologia tropical. Rio de Janeiro: Editora FIOCRUZ, 2011. 298p. 
FIGUEIREDO, Betânia Gonçalves. 'As doenças dos escravos: um campo de estudo para a história das ciências da saúde', In: Uma história brasileira das doenças. Rio de Janeiro: Mauad X, 2006, p. 252-274.

FREITAS, Octavio de. Doenças africanas no Brasil. São Paulo: Cia Ed. Nacional. 1935.

GUIMARÃES, Maria R. Cotrim. 'Os manuais de medicina popular do Império e as doenças dos escravos: o exemplo do 'Chernoviz', In Revista Latinoamericana Psicopatologia Fundamental. v. 11, n. 4 , p. $827-840$, dez. 2008

KARASCH, Mary C. A vida dos escravos no Rio de Janeiro (1808-1950). São Paulo: Companhia das Letras, 2000.

LENT, Herman; FREITAS, J. F. Teixeira de. 'Alguns helminthos da collecção de Pedro Severiano de Magalhães', In Memórias do Instituto Oswaldo Cruz, Rio de Janeiro, v. 32, n. 2, p. 305-309, 1937.

LIMA, Silvio Cezar de Souza. O corpo escravo como objeto das práticas médicas no Rio de Janeiro (1830-1850). Tese (Doutorado em História das Ciências e da Saúde) - Fundação Oswaldo Cruz. Casa de Oswaldo Cruz, 2011. 208p.

LOPES, Maria Margaret; HEIZER, Alda (Org.). Colecionismo, prática de campo e representações. Campina Grande: EDUEPB, 2011. 284p.

MORAES, Mário Augusto Pinto de. 'Dermatoses por helmintos', In ARS Cvrandi, v. 7, n. 6, p.108122, set. 1974.

NORONHA, Dely. 'Coleção Helmintológica do Instituto Oswaldo Cruz (CHIOC)', In: I Simpósio Nacional de Coleções Científicas: Evento comemorativo aos 105 anos do Instituto Oswaldo Cruz. Rio de Janeiro: IOC. FioCruz, 2005. Fls. 51-52.

NORONHA, Dely et al. Adolpho Lutz e a Coleção de Helmintologia do Instituto Oswaldo Cruz. Rio de Janeiro: Museu Nacional, 2009. 154p.

PEREIRA. Manoel Victorino. 'A Filaria de medina transportada para a America por negros D'Africa; provas de sua endemicidade na província da Bahia, e da sa introdução no corpo humano pelo Estômago', In: Gazeta Médica da Bahia. Bahia: Officina Litho-Typographica de J. G Tourinho, 1877. Pág. 151-166.

PORTO, Ângela. 'O sistema de saúde do escravo no Brasil do século XIX: doenças, instituições e práticas terapêuticas', In. História, ciências, saúde - Manguinhos, Rio de Janeiro, v. 13, n. 4, p. 1019-1027, Dec. 2006.

RACHOU, René Guimarães. 'Distribuição geográfica das filarioses humanas no Brasil', In. Revista Brasileira de Malariologia e Doenças Tropicais, v.9, n.1, p.79-100, jan. 1957.

REZENDE. Joffre Marcondes de.'O símbolo da medicina e o verme da Guiné', In: Brasília Med. 2012; 49 (1): 76-78.

SÁ, Magali Romero; MAIA-HERZOG, Marilza. 'Doença de além-mar: estudos comparativos da oncocercose na América Latina e África', In. História, ciências, saúde - Manguinhos, Rio de Janeiro, v. 10, n. 1, p. 251-258, Apr. 2003. 
SIGAUD, Joseph François Xavier. Do clima e das doenças do Brasil ou estatística médica deste Império. Rio de Janeiro: Fiocruz, 2009.

STEPAN, Nancy. Gênese e evolução da ciência brasileira: Oswaldo Cruz e a política de investigação científica e médica. Rio de Janeiro: Editora Artenova s.a, 1976. 188p.

\section{Sites:}

Adolpho Lutz. Capturado em 20 de junho de 2021. Online: Disponível na Internet:

http://www.ioc.fiocruz.br/pages/personalidades/AdolphoLutz.htm.

Coleção Helmintológica do Instituto Oswaldo Cruz. Capturado em 20 jan. 2021. Online. Disponível na Internet: http://chioc.fiocruz.br/index?history

Lauro Pereira Travassos. Capturado em 20 jan. 2021. Online. Disponível na Internet: http://www.ioc.fiocruz.br/pages/personalidades/LauroPereiraTravassos.htm

José Gomes de Faria. Capturado em 20 jan. 2021. Online. Disponível na Internet: http://www.ioc.fiocruz.br/pages/personalidades/JoseGomesDeFaria.htm

René Guimarães Rachou. Capturado em 20. Jan. 2021. Online. Disponível na internet: http://www.cpqrr.fiocruz.br/pg/rene-guimaraes-rachou/

The Carter Center. Capturado em 20. Jan.2021. Online. Disponível naInternet: https://www.cartercenter.org/health/guinea_worm/

The Transatlantic Slave Trade Database. Capturado em 25. jan. 2021. Online. Disponível na Internet: https://www.slavevoyages.org/assessment/estimates

Vitorino, Manuel. Dicionário Histórico-biográfico Brasileiro - DHBB. Capturado em 25. Jan. 2021. Online. Disponível na Internet: http://cpdoc.fgv.br/sites/default/files/verbetes/primeirarepublica/VITORINO,\%20Manuel.pdf. 